\title{
Self-Selection Bias in Estimating the Determinants of Landowners' Re-enrollment Decisions in Forest Incentive Programs
}

\author{
$\operatorname{AUTHOR}(\mathrm{S})$ :
}

Mitani, Yohei; Shimada, Hideki

\section{CITATION:}

Mitani, Yohei ... [et al]. Self-Selection Bias in Estimating the Determinants of Landowners' Re-enrollment Decisions in Forest Incentive Programs. NRE-DP: Natural Resource Economics Discussion Papers 2021, 2021-01: 0-21

\section{ISSUE DATE:}

2021-05-31

URL:

http://hdl.handle.net/2433/264250

\section{RIGHT:}

This is a preprint of the published article: Yohei Mitani and Hideki Shimada (2021), "Selfselection bias in estimating the determinants of landowners' Re-enrollment decisions in forest incentive programs, "Ecological Economics, Volume 188, 107109.

https://doi.org/10.1016/j.ecolecon.2021.107109.; All rights are reserved by the authors. 
NRE Discussion Papers No. 2021-01

June 2021

Division of Natural Resource Economics, Graduate School of Agriculture, Kyoto University

Self-Selection Bias in Estimating the Determinants of Landowners' Re-enrollment Decisions in Forest Incentive Programs

Yohei Mitani* and Hideki Shimada

May 31, 2021

Natural Resource Economics Discussion Papers are preliminary research reports by members of the GSA-NRE Kyoto University circulated for comments and suggestions. They have not been externally peer-reviewed or been subject to the review by the editorial board. All rights are reserved by the authors. 


\title{
Self-Selection Bias in Estimating the Determinants of Landowners' Re- enrollment Decisions in Forest Incentive Programs
}

\author{
Yohei Mitani* and Hideki Shimada
}

This is a preprint of the published article: Yohei Mitani and Hideki Shimada (2021), "Self-selection bias in estimating the determinants of landowners' Re-enrollment decisions in forest incentive programs," Ecological Economics, Volume 188, 107109. https://doi.org/10.1016/j.ecolecon.2021.107109.

\begin{abstract}
Despite increasing attention in recent years, only a very limited number of studies have investigated the determinants of landowner re-enrollment intention in conservation incentive programs, none of which controlled for the potential self-selection of participants. This concern for a self-selection bias is policy relevant because researchers and policymakers investigate the determinants of re-enrollment in order not only to predict the retention rate of participants but also to promote the long-term success of conservation programs. This paper uses data on eligible landowners, consisting of both participants and non-participants, from a forest incentive program in Japan to examine the determinants of the participant re-enrollment decision, controlling for a rich set of observable landowner attributes and conditioned on the unobserved participant attributes identified by modeling the re-enrollment decision jointly with the decision to participate. The empirical results indicate that the unconditional marginal effects from the separate re-enrollment model are biased by selection and underestimate the effects by between $12 \%$ and $48 \%$. The results also show that the observable factors that attract landowners to participate also tend to encourage participants to remain in the program. This implies that interventions directed at increasing initial participation are also likely to increase re-enrollment.
\end{abstract}

\section{Keywords}

Forest incentive program; Agri-environmental program; Private land conservation; Reenrollment; Participation; Self-selection bias; Policy design

\begin{tabular}{ll} 
Authors & \multicolumn{1}{c}{ Yohei Mitani* } \\
\hline * Corresponding author. & JSPS Research Fellow Shimada \\
Associate Professor & Division of Natural Resource Economics, \\
Division of Natural Resource Economics, & Graduate School of Agriculture, \\
Graduate School of Agriculture, & Kyoto University \\
Kyoto University & Kyoto, 606-8502, Japan \\
Kyoto, 606-8502, Japan & shimada.hideki.47n@st.kyoto-u.ac.jp \\
0081-75-753-6193 & \\
mitani.yohei.7w@kyoto-u.ac.jp & \\
yomitani@gmail.com & \\
\hline
\end{tabular}

Last updated: October 22, 2020 


\section{Introduction}

Voluntary incentive programs have become a major policy instrument for private land conservation in most developed countries (Hanley et al., 2012; Hellerstein, 2017; Kamal et al., 2015). Eligible landowners have the freedom to choose whether or not to enroll their land in such programs. Participants receive incentive payments in exchange for the changes of land uses or for land retirements that additionally deliver a flow of ecosystem services. Most such voluntary-based incentive programs, including the United States Conservation Reserve Program (CRP) and the EU Agri-Environmental Schemes (AES), have contract lengths of 20 years or less (Kuhfuss et al., 2016). Given these fixed-term contracts, the long-term success of such programs, delivered through the continuation of the conservation efforts, hinges on participants' willingness to renew their contracts when they expire (Engel et al., 2008; Stubbs, 2014). The study of the determinants of landowners' re-enrollment decisions has received increasing attention, especially in recent years, due to the fact that a large number of CRP and AES contracts have expired or are approaching expiration.

Understanding landowners' intentions to leave or remain in such a conservation incentive program at the end of its initial contract period is crucial for long-term policy success. First, continued participation contributes to the long-term conservation of private land. Early withdrawers tend to cease their conservation efforts and return to their original practices (e.g. crop production, grazing, or timber production) after leaving the program (Roberts and Lubowski, 2007; Riley, 2016). Also, the chance of continuing conservation efforts after financial incentives end increases as the length of time remained in the program increases (Reimer et al., 2014; Dayer et al., 2018). Second, in theory, the optimal design of incentive programs involves a choice of contract length (Ando and Chen, 2011; Shah and Ando, 2016). Longer contract duration would significantly reduce uncertainty in the future and can be positively correlated with the long-term performance of conservation programs (Mitani and Lindhjem, 2015). On the other hand, longer contract duration is expected to reduce the initial participation rates that may, at the same time, severely limit the conservation performance (Lienhoop and Brouwer, 2015; Rabotyagov and Lin, 2013; Yeboah et al., 2015). To capture the impact of policy design, a deeper understanding of the determinants driving landowner re-enrollment intentions is required for policymakers. 
Although a large number of studies have investigated the determinants of landowner initial participation (e.g. Lastra-Bravo et al., 2015; Langpap and Kim, 2010; Mitani and Lindhjem, 2020), little effort has been made to study their intentions to leave or remain in the program at the end of the contract period (Riley, 2016; Defrancesco et al., 2018; Lutter et al., 2019). An increasing, but still limited, number of studies have focused on program-participant behavior upon contract expiry. This relatively new stream in the literature can be classified into three groups, according to dependent variable (i.e. target behavior). The first strand of research examines the post-program, persistent behavior of participants (Roberts and Lubowski, 2007; Kuhfuss et al., 2016; Dayer et al., 2018). These studies investigate whether and why landowners voluntarily continue the conservation practices prompted by program participation after the contract ends and also explore what encourages persistence of conservation behavior in the absence of monetary compensation. The second type of research examines participants' multiple choices for land-use alternatives at the end of their contracts (Caldas et al., 2016; Lutter et al., 2019). These studies investigate the determinants of program participants' intentions 1) to re-enroll in the program;2) to leave it but voluntarily continue conservation practices; or 3 ) to drop out and return to production. The third strand of research focuses on a participant's binary re-enrollment choice, whether to leave or remain in the program at the end of the contract, which is our focus in this paper. Early re-enrollment studies investigate the impact of incentive payments on landowner intentions to renew their contract when it expires (Cooper and Osborn, 1998; Chen et al., 2009). They show a positive association between incentive payments and the likelihood of intended re-enrollment for contract holders. Wallander et al. (2017) conducted a large-scale natural field experiment within the CRP and find that information outreach can stimulate greater re-enrollment among currently enrolled farmers in the CRP. Defrancesco et al. (2018) use a time-series panel data of AES participants to investigate what influences their decision on whether or not to remain in the scheme. They find that time-variant variables, such as policy changes, as well as farmer characteristics, can be associated with longer continued membership in the scheme.

Although recent research has provided significant insights into a better understanding of program-participant behavior at the end of the contract, a major technical concern remains with all of the studies cited above: none of them has controlled for potential 
selection bias. The re-enrollment decision is conditional on the participation decision, and these decisions are likely to be correlated because they would depend on many of the same observed and unobserved landowner characteristics and their program interactions. The two stages of the decision process must be examined jointly, otherwise the estimated marginal effect of observable characteristics on re-enrollment will be biased and inconsistent due to selection (Heckman, 1979). For example, policymakers may be interested in the effectiveness of information outreach and whether landowners who are well-informed about the program are more likely to renew their contracts. The literature indicates that well-informed landowners are more likely to participate in the program (Langpap and Kim, 2010). Estimating the marginal impact of program familiarity on re-enrollment using participant behavior may lead to an underestimation of its true impact due to the lack of consideration of unfamiliar landowners who were eligible but did not participate in the program. This selection bias concern calls into question the unconditional marginal effects of observable characteristics on re-enrollment that are estimated based solely on participants' choices.

This concern is policy relevant and potentially important because researchers and policymakers investigate the determinants of re-enrollment decisions in order not only to predict the retention rate of participants but also to promote the long-term success of the program. To achieve long-term successful conservation, policymakers are often interested in evaluating policy interventions that increase the likelihood of reenrollment as well as initial participation. Furthermore, identifying the landowner characteristics that increase the likelihood of re-enrollment helps program managers target landowners who are more likely to remain in the program for a longer period of time. In these cases, the population of interest should be all eligible landowners rather than participants.

To investigate this concern, this paper uses data on eligible landowners, including participants and non-participants, to examine the impact of observable characteristics on re-enrollment, controlling for a detailed set of observable landowner characteristics and conditioned on the unobserved participant characteristics identified by modeling the re-enrollment decision jointly with the decision to participate. We chose as a case study the Kuma Joint Management Program, which has the second longest history (and the largest enrolled land area) as forest incentive schemes in Japan and aims at assisting 
sustainable forest management and conservation on private land. Registration data were combined with a rich set of explanatory variables obtained from a mail survey, in which 1,006 eligible landowners were asked if they had enrolled in the program and then participants were further asked about their intention to leave or remain in the program at the end of the initial contract period. The empirical results suggest that the observed factors that attract landowners to program participation also tend to encourage them to remain in the program at the end of the initial contract. This implies that policy interventions directed at increasing initial participation are also likely to increase reenrollment. The findings also indicate that the unobserved attributes that make landowners more likely to participate also cause them to be more likely to re-enroll, suggesting that the self-selection of participants matters in forecasting participant reenrollment probability. This confirms the potential selection bias concerns in prior work on re-enrollment.

\section{Study Site and Policy Context}

Our study site, Kuma-kogen town (hereafter, the Kuma municipality), is located in the center of Ehime prefecture $\left(33^{\circ} 39^{\prime} \mathrm{N}, 132^{\circ} 54^{\prime} \mathrm{E}\right)$, approximately $600 \mathrm{~km}$ southwest of Tokyo (Figure 1). The municipality is very mountainous and has 43,169 hectares private forestland, which is $83.3 \%$ of the total forestland and $74.0 \%$ of the total land $\left(583.7 \mathrm{~km}^{2}\right)$ in the municipality (Ministry of Agriculture Forestry and Fisheries, 2019). Forestry activity in the area had been successful until 1980s because of increasing domestic timber demands associated with the economic growth of Japan. However, many private forest landowners ${ }^{1}$ lost their motivation for timber productions as timber prices began to decline. In order to promote sustainable forest management and conservation on private land in the municipality, the Kuma Joint Management (KJM) program was introduced in 2006 by the Kuma Forest Association (KFA), the local forest agency in the municipality. The KJM program has the second longest history and the largest enrolled land area as forest incentive schemes in Japan.

\footnotetext{
${ }^{1}$ Most landowners owing forest in the municipality are small-scale, non-industrial private forest owners. In our sample, the median size of forest owned is 4.02 ha. Just less than a quarter (23.2\%) of the landowners in our sample own forest larger than 10 hectares. Only $1.8 \%$ of the landowners in our sample own forest larger than 50 hectares.
} 


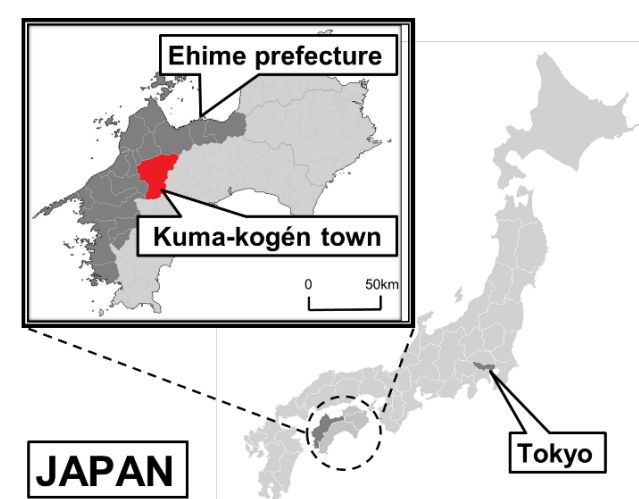

Figure 1: The Location of Kuma-kogen Town

Generally speaking, forests, in Japan, provide a variety of environmental services such as habitat for wildlife, carbon sequestration, recreational opportunities, and flood and landslide prevention. Extensive afforestation took place during the 1950s through the 1970s, during which time conifers were planted in huge areas to meet the growing demand for timber created by rapid economic growth. However, forest landowner motivations for carrying out forest management have been diminishing with declining timber prices and the aging of forest landowners (Forestry Agency of Japan, 2017). ${ }^{2}$ A lack of consistent, active forest management in recent decades has led to the deterioration and decline of these forest environmental services. Another characteristic in Japan is small-scale forestland ownership. ${ }^{3}$ This small-scale ownership incurs higher unit costs and therefore discourages forest management. To prevent any further deterioration in environmental services provided by small-scale private forests, the Forest Agency of Japan launched subsidy schemes, with an annual goal of supporting 520,000 hectares of private forestland (which is equivalent to $2.1 \%$ of the total forestland in Japan) to be sustainably managed (Forestry Agency of Japan, 2017). The

\footnotetext{
${ }^{2}$ The stumpage price of the Japanese cedar (Cryptomeria japonica) drastically declined from 22,707 $\mathrm{JPY} / \mathrm{m}^{3}$ in 1980 to $2,995 \mathrm{JPY} / \mathrm{m}^{3}$ in 2015. During this period, the number of people involved in forest management declined from 146,321 to 45,440, and the percentage of the population that was elderly, that is, aged 65 or older, increased from $8 \%$ to $25 \%$. Note that the number reflects those who derive income from any forestry activity during the period. Hence, it includes industrial and non-industrial private forest owners as well as non-owners.

${ }^{3}$ For example, $74 \%$ of those who possessed at least one hectare owned less than five hectares in 2016 (Forestry Agency of Japan, 2017).
} 
KJM program is the second regional program in Japan, designed under this national subsidy scheme. ${ }^{4}$

The KJM program seeks to implement joint management of continuous forestland that has several owners so that environmental services would be enhanced in such larger areas than single-ownership parcels. It is an incentive-based program in which forest owners receive lump-sum payments in exchange for transferring all their rights, except for ownership and access to the forest, to the KFA for a period of five years. The KFA determines the payment amount based on timber income from thinning, management costs, and subsidies from the government. ${ }^{5}$ To proceed to the management step, the KFA needs to decide if a joint area is to be managed based on the spatial configuration of enrolled forest. When the targeted area contains unenrolled forest parcels, the KFA often directly approaches any non-participants and persuades them to also participate in the KJM program. Once all parcels in the targeted area are under contract, the KFA then develops a management plan, obtains the approval of forest owners, implements joint forest management efforts, and makes payments to the forest owners. Although they are supposed to enroll for five-year periods, owners can request early termination of their contracts.

In Figure 2, we illustrate KJM program development since its launch in 2006 in terms of the number of participants and the total area of enrolled forest. It shows that both the number of participants and the total area of land under management have been increasing, though there was a slight decline in the number of participants in 2012. Figure 3 depicts the spatial configuration of enrolled forestlands in 2011. Among 92,990 forest plots, 11,450 plots (about 12\%) were under contract.

\footnotetext{
${ }^{4}$ See Appendix I for details regarding Japanese forest incentive schemes.

${ }^{5}$ The average estimated payment was 29,040 JPY/ha (267 USD/ha, November 2019 exchange rates).
} 


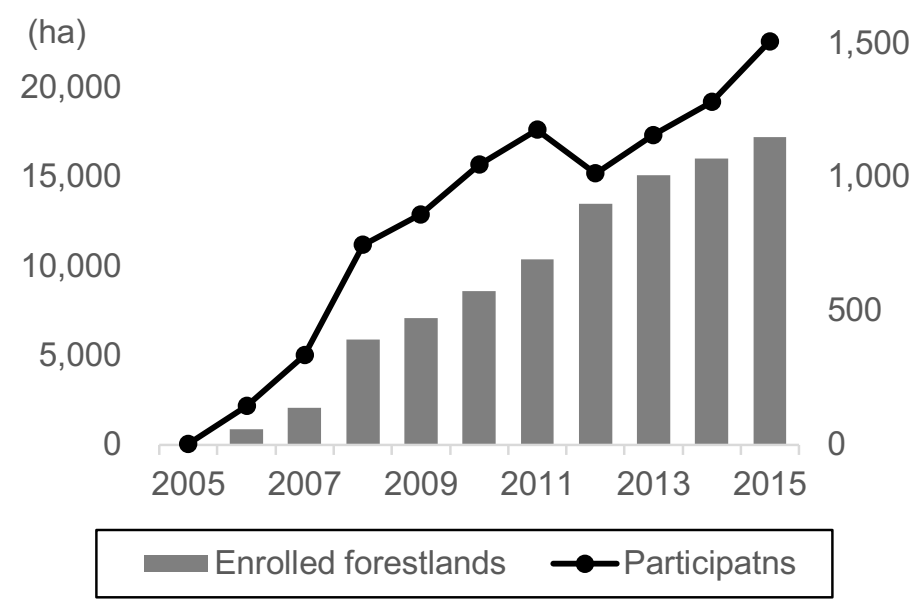

Figure 2: The Number of Participants and Size of Enrolled Areas

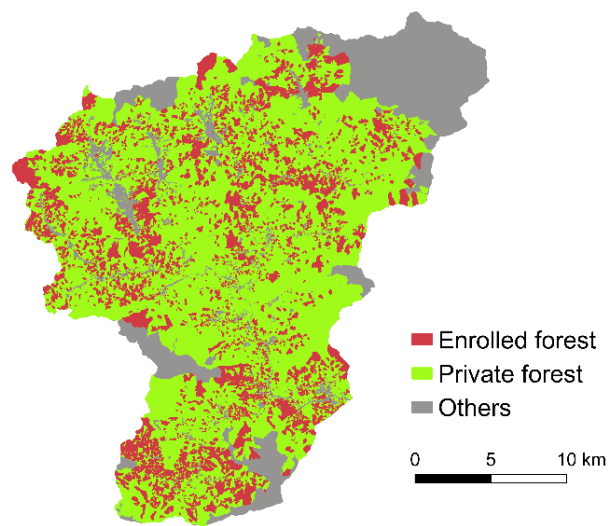

Figure 3: Spatial Configuration of Enrolled Forest (as of 2011)

\section{Data}

\subsection{Survey Design and Administration}

Two data sources are merged in order to analyze initial participation and re-enrollment in the KJM program. The first source is the census data of the KFA members as provided by the KFA. The census data record all members' actual contract status of the KJM program, their addresses, total size of forest owned, and total size of forest under contract. The second data source is a mail survey designed to elicit information about the individual characteristics of landowners. The questionnaire consists of five main sections, and we use three of them for our analysis. ${ }^{6}$

\footnotetext{
${ }^{6}$ The English translated version is available upon author request.
} 
The first section contained questions about forest property, the frequency of forest management activities, and landowner motivation for owning forestland. In addition, landowners were asked if they had any experience with joint forest management with neighboring owners before the KJM program was launched in 2006. The second section contained questions related to the KJM program and the KFA. These questions began by asking landowners about their degree of knowledge about the program, followed by a question on whether landowners participated in the program. Those who answered yes were then asked about their willingness to re-enroll in the program at the end of the contract, where the available alternatives were "I will renew my contract," "I will not renew my contract and manage my forest on my own," "I will not renew my contract and ask someone else to manage it," or "I will neither renew my contract nor manage my forest."7 The response to this question, which measures owner intention to re-enroll, is the primary variable of interest in this paper. We assumed that landowners intend to re-enroll in the program if they selected the first alternative, "I will renew my contract." All landowners were also asked about how often they utilized KFA services in the past five years. In the final section, we asked landowners questions about their background demographic information, including gender, age, job, postal code, education, and membership in various organizations.

A list of names and addresses of landowners who owned forests in the municipality was extracted from the census data. This list contained the most correct and broadest registry of all those available. From the registry of 3,535 landowners, those who qualified as industrial private owners, who did not possess forestland in the municipality, who refused to receive any questionnaire, or whose addresses were unknown were excluded from the sample. A total of 2,286 landowners remained after this exclusion process. In December 2011, we mailed surveys to all eligible owners, followed by a reminder sent 10 days after the initial letter. The total number of respondents totaled 1,160 and the overall response rate was $50.74 \%$. After excluding incomplete questionnaires, we obtained the final sample size of $1,006 .{ }^{8}$

\footnotetext{
${ }^{7}$ See Appendix II for the exact question wording.

${ }^{8}$ Since our data are partly generated by a survey, we test a potential nonresponse bias by comparing available characteristics, such as forest size, participation status, and residence status, between our
} 


\subsection{Variables and Descriptive Statistics}

Table 1 summarizes the variables used in our estimation, their definitions, means, and standard deviations. The first two variables in Panel A, Participant and Re-enrollment, respectively, represent the status of initial participation $\left(d_{i}\right)$ and re-enrollment $\left(y_{i}\right)$. The descriptive statistics shows that $36 \%$ of landowners participate in the KJM program. Among them, most landowners (88\%) intend to re-enroll in the program. The high interest in re-enrollment is in line with the findings of Barnes et al. (2019), who reported that over $83 \%$ of the sample participants in the CRP showed an interest in re-enrollment.

Panel B of Table 1 reports on the set of independent variables. We chose these variables based on the large literature on non-industrial private forest landowners' voluntary participation (Mitani and Lindhjem, 2020) since there were a limited number of papers investigating their re-enrollment behavior.

We included two variables relevant to the KJM program and transaction cost regarding the program for landowners: whether a landowner is familiar with the program (WellInformed) and whether a landowner was directly approached by the KFA (Approached). First, the literature shows that familiarity with a program plays an important role in program participation (Bell et al., 1994; Dahl et al., 2014; Duflo and Saez, 2003; Kilgore et al., 2008). Higher knowledge about the program would be associated with lower transaction costs, would reduce the effort required for landowners to obtain additional information, and would reduce their uncertainty about the program. Hence, Well-Informed is expected to have a positive coefficient in the first and second stages. Second, we expected a positive coefficient of Approached in the first stage. An

final sample $(\mathrm{N}=1,006)$ and the census data $(\mathrm{N}=2,286)$. Pearson's chi-squared test does not detect a statistically significant difference in the residence status (whether the landowner lives in the Kuma municipality) at the $5 \%$ level $\left(\chi^{2}=0.0003, p=0.987\right)$. However, Mann-Whitney $\mathrm{U}$ and Pearson's chi-squared tests find statistically significant differences in the forest size $(z=-4.313$, $p<0.001)$ and participation status $\left(\chi^{2}=23.32, p<0.001\right)$, respectively. This suggests that the landowners in our sample tend to own larger forest and are more likely to participate in the program compared with all landowners in the census, implying that results in the following sections require cautions to be generalized. 
approach by the KFA would significantly reduce the costs incurred by a landowner during the contract, which would enhance participation. Beyond initial contract, this variable is expected to have a positive coefficient in second-stage re-enrollment. This is because the approach can incur reciprocity on the part of landowners, encouraging re-enrollment (Fehr and Gächter, 2000).

Table 1: Definition of Variables and Descriptive Statistics

\begin{tabular}{|c|c|c|c|c|c|}
\hline \multirow[b]{2}{*}{ Variable } & \multirow[b]{2}{*}{ Description } & \multicolumn{2}{|c|}{ All Sample } & \multicolumn{2}{|c|}{ Participants } \\
\hline & & Mean & S.D. & Mean & S.D. \\
\hline \multicolumn{6}{|c|}{ Panel A. Dependent Variables } \\
\hline Participant & 1 if the owner has participated in the program (first stage) * & 0.36 & 0.48 & 1.00 & 0.00 \\
\hline Re-enrollment & 1 if the owner is willing to renew the contract (second stage) $*$ & - & - & 0.88 & 0.32 \\
\hline \multicolumn{6}{|c|}{ Panel B. Independent Variables } \\
\hline Well-Informed & 1 if the owner is familiar with the program* & 0.64 & 0.48 & 0.87 & 0.33 \\
\hline Approached & 1 if the owner was directly approached by the forest association* & 0.25 & 0.43 & 0.39 & 0.49 \\
\hline Border & Recognizing the borders of his forest (5-scale, 1 : not at all; 5 : fully) & 3.97 & 1.21 & 3.85 & 1.24 \\
\hline Bequest & 1 if the owner has bequest intentions and his successor will inherit* & 0.74 & 0.44 & 0.79 & 0.41 \\
\hline Management & 1 if the owner has been involved in forest management every year* & 0.17 & 0.38 & 0.15 & 0.36 \\
\hline Revenue & $\begin{array}{l}1 \text { if the owner agrees with the importance of timber revenue in terms of } \\
\text { his ownership objectives* }\end{array}$ & 0.38 & 0.48 & 0.44 & 0.50 \\
\hline Watershed & $\begin{array}{l}1 \text { if the owner agrees with the importance of watershed protection and } \\
\text { other social benefits in terms of his ownership objectives* }\end{array}$ & 0.52 & 0.50 & 0.59 & 0.49 \\
\hline Wildlife & $\begin{array}{l}1 \text { if the owner agrees with the importance of wildlife habitat } \\
\text { conservation in terms of his ownership objectives* }\end{array}$ & 0.24 & 0.43 & 0.29 & 0.45 \\
\hline Male & 1 if gender of owner is male* & 0.86 & 0.35 & 0.82 & 0.39 \\
\hline Age & Age of owner (continuous) & 70.2 & 10.8 & 69.9 & 10.7 \\
\hline Employment & 1 if the owner is employed by a private company or public sector* & 0.15 & 0.36 & 0.17 & 0.37 \\
\hline Farmer & 1 if the owner is also engaged in farming* & 0.32 & 0.47 & 0.25 & 0.43 \\
\hline Education & 1 if the owner has at least a bachelor's degree* & 0.15 & 0.35 & 0.20 & 0.40 \\
\hline Residence $^{\dagger}$ & 1 if the owner is resident in the Kuma municipality* & 0.63 & 0.48 & 0.52 & 0.50 \\
\hline Forest-Size ${ }^{\dagger}$ & Registered forest size in hector divided by 10 (continuous) & 0.83 & 0.17 & 0.11 & 0.25 \\
\hline Joint-Manage & 1 if the owner has jointly managed his forest with neighbors* & 0.31 & 0.46 & 0.44 & 0.50 \\
\hline No-Use-FA & 1 if the owner has never used any service of the $\mathrm{FA}^{*}$ & 0.50 & 0.50 & 0.33 & 0.47 \\
\hline
\end{tabular}

* Dummy variable.

$\dagger$ Retrieved from the census data.

The next three variables, recognition of forest borders (Border), whether a landowner has bequest intentions and had decided who would succeed them in ownership of their 
forest (Bequest), and whether they have been involved in forest management every year (Management), are thought to be associated with the opportunity cost of participation. Landowners who recognized the border or had chosen successors would be more attached to the forest and keep them close at hand. ${ }^{9}$ Similarly, those who conducted forest management activities every year would be more likely to have their own management intention regarding both timber and non-timber activities as well as be reluctant to participate in the program. The variables related to opportunity cost are thus predicted to have a negative impact on participation and re-enrollment.

We also controlled for a landowner's objectives of ownership (Revenue, Watershed, and Habit). The literature suggests that a positive attitude toward conservation tends to enhance participation in a conservation program (Langpap, 2004; Mitani and Lindhjem, 2015). Hence, the coefficients of Watershed and Habit are expected to be positive.

Finally, we controlled for landowner's gender (Male), age (Age), job (Employment and Farmer), education level (Education), whether or not they lived in the Kuma municipality (Residence), and the forest-size recorded in census data in hectares (Forest-Size). Chen et al. (2009) reported that the first two characteristics significantly affected re-enrollment behavior. Also, the literature suggests that education level is a very significant determinant of program participation (Beach et al., 2005; Langpap and Kim, 2010). The literature reports that the opportunity cost for program participation is negatively correlated with absentee ownership, suggesting that Residence is expected to have a negative coefficient in the both stages (Lindhjem and Mitani, 2012). In addition, Forest-Size is expected to have a positive coefficient in the both stages since a larger forest is associated with a larger total payment.

\footnotetext{
${ }^{9}$ Interestingly, many Japanese small-scale private forest owners do not recognize their property line. This variable (Border) reflects how much connected landowners are to their forest. Only $42.4 \%$ of respondents answered they recognized the border of their forest entirely, while $5.9 \%$ of them answered they did not recognize it at all.
} 


\section{Econometric Analysis}

\subsection{Estimation Strategy}

The primary objective of this paper is to investigate the factors that affect landowners' willingness to re-enroll in forest incentive programs, conditioning on participation. Thus, re-enrollment can be modeled as the result of a sequence of decisions whereby eligible landowners first choose to participate in the program, and then subsequently decide whether or not to renew their contracts when they expire.

First, we model the re-enrollment decision as follows:

$$
y_{i}=1\left[\mathbf{x}_{i} \boldsymbol{\beta}+u_{i} \geq 0\right]
$$

where $y_{i}$ is a dummy variable that equals 1 if the landowner $i$ is willing to re-enroll, $\mathbf{x}_{i}$ is a vector of their individual characteristics, the coefficients $\boldsymbol{\beta}$ are the parameters of our interest, and $u_{i}$ represents unobservable factors on the re-enrollment decision. The function $1[\cdot]$ is an indicator function that takes the value of 1 if a statement in the bracket is true and a value of 0 otherwise. Assuming that $u_{i}$ is normally distributed with a mean of zero and unit variance, we can derive the probability of re-enrollment conditional on $\mathbf{x}_{i}$ as follows:

$$
\operatorname{Pr}\left(y_{i}=1 \mid \mathbf{x}_{i}\right)=\boldsymbol{\Phi}\left(\mathbf{x}_{i} \boldsymbol{\beta}\right),
$$

where $\boldsymbol{\Phi}$ represents the cumulative distribution function (CDF) of the standard normal distribution. Note, however, that this conditional probability does not consider the fact that re-enrollment decisions are made only by participants. Since the population of interest is all eligible landowners, we have to condition re-enrollment probability on participation status. Unless re-enrollment decision is independent of initial participation decision, an estimator based on the conditional probability (2) is inconsistent, which is known as sample selection bias (Heckman, 1979).

To deal with the possible correlation, we model initial participation and incorporate it into the re-enrollment decision function (Heckman, 1979; Van de Ven and Van Pragg, 1981). In other words, the jointness of participation and re-enrollment decisions is utilized in our empirical model in order to estimate the marginal effects of observable characteristics on re-enrollment conditioned on unobservable factors that are revealed in the decision to participate. We model the initial participation decision as follows:

$$
d_{i}=1\left[\mathbf{z}_{i} \boldsymbol{\delta}+v_{i} \geq 0\right]
$$


where $d_{i}$ is equal to 1 if the landowner $i$ participates in the program and 0 otherwise, and $v_{i}$ represents unobservable factors on participation that are normally distributed with a mean of zero and unit variance. $\mathbf{z}_{i}$ is a vector of $i$ 's individual characteristics, which are independent of $\left(u_{i}, v_{i}\right)$ and contain both $\mathbf{x}_{i}$ and some other variables that are excluded from (1). Assuming that $u_{i}$ and $v_{i}$ are bivariate standard normally distributed with $\operatorname{Corr}\left(u_{i}, v_{i}\right)=\rho$, the re-enrollment probability conditional on $\mathbf{x}_{i}$ and participation $\left(d_{i}=1\right)$ is expressed as:

$$
\operatorname{Pr}\left(y_{i}=1 \mid \mathbf{x}_{i}, d_{i}=1\right)=\frac{1}{\boldsymbol{\Phi}\left(\mathbf{z}_{i} \boldsymbol{\delta}\right)} \int_{-\mathbf{z}_{i} \boldsymbol{\delta}}^{\infty} \boldsymbol{\Phi}\left[\frac{\mathbf{x}_{i} \boldsymbol{\beta}+\rho s}{\sqrt{1-\rho^{2}}}\right] \phi(s) d s,
$$

where $\phi(\cdot)$ is the standard normal density (Wooldridge, 2010). ${ }^{10}$ If $\rho \neq 0$, the estimators using (2) are inconsistent. Deriving the likelihood of initial participation based on (3) and combining it with the likelihood of re-enrollment obtained from (4), we can consistently estimate $\left(\boldsymbol{\beta}^{\prime}, \boldsymbol{\delta}^{\prime}, \rho\right)$ using the maximum likelihood estimation method (Greene, 2003).

To identify parameters, at least one variable is required to be excluded from the reenrollment equation (1). The excluded variable(s) has a direct association with participation behavior but does not directly influence re-enrollment intention. We excluded two variables that were related to the transaction costs of the landowner's initial participation, which would be minimized after initial participation. The first variable to be excluded was the experience of joint management (Joint-Manage). This variable would lower the transaction costs of initial participation, since those who have experienced joint management are thought to know more about joint management. Hence, the effect of experience would disappear once a landowner participates in the KJM program. The second excluded variable was how often a landowner had previously utilized services provided by the KFA (No-Use-FA). This variable represents the existence of a relationship between a landowner and the KFA. This variable can be excluded from the re-enrollment equation since in order to participate in the KJM program by signing a contract with the KFA, a landowner must meet KFA staff, which serves to build relationships. Namely, after initial participation, all participants have a relationship with the KFA.

\footnotetext{
${ }^{10}$ See Appendix III for derivation of equation (4).
} 


\subsection{Estimation Results and Discussion}

Table 2 represents our estimation results. Columns (1) and (2) report the estimates obtained through joint estimation (Model 1 Joint) and correspond to the first-stage participation and second-stage re-enrollment equations, respectively. In column (3), we report the estimates of the re-enrollment equation without considering the first-stage equation (Model 2 Separate). Columns (2) and (3) in Table 3 show the marginal effects of estimates of the re-enrollment equation that are obtained by joint and separate estimations, respectively.

Table 2: Estimation Results

\begin{tabular}{|c|c|c|c|c|c|c|}
\hline & \multicolumn{4}{|c|}{ Model 1 Joint } & \multirow{2}{*}{\multicolumn{2}{|c|}{$\begin{array}{c}\text { Model } 2 \text { Separate } \\
\text { (3) Re-enrollment }\end{array}$}} \\
\hline & \multicolumn{2}{|c|}{ (1) Participation } & \multicolumn{2}{|c|}{ (2) Re-enrollment } & & \\
\hline & Coef. & S.E. & Coef. & S.E. & Coef. & S.E. \\
\hline Well-Informed & $1.083 * * *$ & 0.121 & $1.267 * * *$ & 0.243 & $0.835 * * *$ & 0.270 \\
\hline Approached & $0.318 * * *$ & 0.108 & $0.353^{*}$ & 0.198 & 0.164 & 0.220 \\
\hline Border & $-0.166^{* * *}$ & 0.046 & $-0.329 * * *$ & 0.113 & $-0.334 * *$ & 0.131 \\
\hline Bequest & $0.211^{*}$ & 0.113 & 0.036 & 0.211 & -0.027 & 0.240 \\
\hline Management & $-0.486 * * *$ & 0.134 & -0.086 & 0.249 & 0.000 & 0.269 \\
\hline Revenue & 0.043 & 0.102 & 0.099 & 0.190 & 0.073 & 0.218 \\
\hline Watershed & 0.027 & 0.101 & $0.429 * *$ & 0.205 & $0.473 * *$ & 0.227 \\
\hline Wildlife & 0.038 & 0.108 & $0.363^{*}$ & 0.207 & 0.335 & 0.236 \\
\hline Male & $-0.481 * * *$ & 0.147 & -0.115 & 0.242 & 0.065 & 0.264 \\
\hline Age & $0.009 *$ & 0.005 & 0.017 & 0.011 & 0.015 & 0.013 \\
\hline Employment & 0.072 & 0.147 & 0.629 & 0.409 & 0.675 & 0.460 \\
\hline Farmer & -0.186 & 0.114 & 0.229 & 0.219 & 0.326 & 0.244 \\
\hline Education & 0.128 & 0.133 & 0.119 & 0.295 & -0.012 & 0.324 \\
\hline Residence & $-0.525 * * *$ & 0.106 & $-0.885 * * *$ & 0.248 & $-0.810^{* * *}$ & 0.292 \\
\hline Forest-Size & $0.077^{* *}$ & 0.035 & -0.056 & 0.035 & $-0.072 * * *$ & 0.025 \\
\hline Joint-Manage & $0.417 * * *$ & 0.103 & & & & \\
\hline No-Use-FA & $-0.636 * * *$ & 0.104 & & & & \\
\hline Constant & -0.520 & 0.388 & -0.287 & 0.770 & 0.838 & 0.848 \\
\hline Rho & $0.632 * *$ & 0.188 & & & & \\
\hline Observations & & & & & 362 & \\
\hline Pseudo $\mathrm{R}^{2}$ & & & & & 0.19 & \\
\hline Log likelihood & & & & & -98.3 & \\
\hline
\end{tabular}


Table 3: Marginal Effects on Re-enrollment

\begin{tabular}{|c|c|c|c|c|}
\hline & \multicolumn{2}{|c|}{ (2) Joint } & \multicolumn{2}{|c|}{ (3) Separate } \\
\hline & Coef. & S.E. & Coef. & S.E. \\
\hline Well-Informed & $0.165 * * *$ & 0.056 & $0.126 * * *$ & 0.040 \\
\hline Approached & 0.044 & 0.042 & 0.025 & 0.032 \\
\hline Border & $-0.056^{* *}$ & 0.025 & $-0.050 * * *$ & 0.019 \\
\hline Bequest & -0.016 & 0.044 & -0.004 & 0.036 \\
\hline Management & 0.036 & 0.050 & 0.000 & 0.040 \\
\hline Revenue & 0.018 & 0.042 & 0.011 & 0.033 \\
\hline Watershed & $0.094^{* *}$ & 0.043 & $0.071^{* *}$ & 0.034 \\
\hline Wildlife & $0.078^{*}$ & 0.047 & 0.050 & 0.036 \\
\hline Male & 0.028 & 0.053 & 0.010 & 0.040 \\
\hline Age & 0.003 & 0.002 & 0.002 & 0.002 \\
\hline Employment & 0.135 & 0.086 & 0.102 & 0.066 \\
\hline Farmer & 0.073 & 0.045 & 0.049 & 0.036 \\
\hline Education & 0.013 & 0.065 & -0.002 & 0.049 \\
\hline Residence & $-0.141 * *$ & 0.055 & $-0.122 * * *$ & 0.041 \\
\hline Forest-Size & $-0.021 * * *$ & 0.008 & $-0.011 * * *$ & 0.004 \\
\hline Observations & 1006 & & 362 & \\
\hline
\end{tabular}

The joint model specification is compared to separate but equivalent specifications using a likelihood ratio test, which yields a chi-square statistics of 3.49 that rejects independence of the re-enrollment decision from the participation decision at the $10 \%$ significance level $(\mathrm{p}=0.061)$. Also, the joint estimation demonstrates that the correlation between the unobservable factors of the first-stage participation and secondstage re-enrollment equations $(\rho)$ is statistically significant at the $5 \%$ level (see Table 2). Hence, if the population of interest is whole eligible landowners rather than participants, the estimator that uses only re-enrollment decision (i.e. Model 2 Separate) is biased. ${ }^{11}$ The positive correlation indicates that once landowners participate in the program, they are more likely to re-enroll in terms of the unobservable factors. The excluded variables, which are presumably related to the transaction costs incurred

\footnotetext{
${ }^{11}$ In Appendix IV, we examine the sensitivity of our estimates by a set of variables. We demonstrate that our estimates are robust for the variable selection (Table A1).
} 
during the initial contract, have a significant effect on first-stage participation. The joint test rejects the null hypothesis that both variables have no effect at the $1 \%$ level $\left(\chi^{2}(2)=56.70\right)$.

Comparing columns (1) and (2), we find that some of the observable determinants have a similar impact on both initial participation and re-enrollment. This implies that if their coefficients are positive (negative) in both behaviors, policymakers are able to achieve long-term conservation by targeting landowners for whom these variables' values are high (low). Familiarity with the program (Well-Informed) and whether or not the KFA directly approached a landowner (Approached) have positive and significant effects on both initial participation and re-enrollment. Similarly, those who live in the Kuma municipality (Residence) and those who recognize forest borders (Border) are less likely to participate or re-enroll in the program. On the other hand, some other variables have different impact. For example, landowners who agree with the importance of watershed protection (Watershed) and wildlife habitat conservation (Wildlife) as part of their ownership objectives are more likely to re-enroll, although these variables do not influence initial participation to any degree of statistical significance. In other words, even if such pro-social motivations for ownership objective do not improve initial participation, they do improve re-enrollment among participants. Therefore, prior knowledge about this discrepancy and targeting based on these pro-social motivations may help policymakers achieve long-term conservation of reserved areas. Table 2 also shows that although those who actively manage their forestland on their own (Manage $=1$ ) are less likely to initially participate in the program, their re-enrollment decision is not influenced by the variable (Manage).

By comparing columns (2) and (3), we examine how ignorance of first-stage participation affects estimates. The statistical significance of some determinants disappears or appears once initial participation and re-enrollment are jointly estimated. For example, Approached and Wildlife are positive and significant under joint estimation while they are statistically insignificant under the separate one. On the other hand, Forest-Size is no longer significant under joint estimation. This suggests that these observed factors are correlated with unobserved factors in the selection process. This result indicates that policymakers who are interested in a priori targeting for long- 
term conservation need to consider the important role of unobserved factors in the initial participation process.

Finally, the comparison between columns (2) and (3) in Table 3 explains to what degree ignorance about initial participation influences the marginal effects of the explanatory variables. The absolute values for marginal effects are larger when first-stage participation is included than when only second-stage re-enrollment is used. For example, the conditional marginal effect of Well-Informed indicates that well-informed participants are $16.5 \%$ more likely to re-enroll, while the separate model estimate indicates a $12.6 \%$ higher re-enrollment probability. The conditional marginal effect of Residence indicates that participants who live in the municipality are $14.1 \%$ less likely to re-enroll, while the separate model estimate indicates a $12.2 \%$ lower re-enrollment probability. Again, this result highlights the potential impact of ignoring unobserved heterogeneity in the selection process.

\section{Concluding Remarks}

This paper uses data on 1,006 eligible landowners, consisting of 357 participants and 649 non-participants, to examine the determinants of the participant re-enrollment decision, controlling for a rich set of observable landowner attributes and conditioned on the unobserved participant attributes identified by modeling the re-enrollment decision jointly with the decision to participate. The empirical results indicate that non-resident landowners of smaller forest land who are not involved in the active management of the forest, have a positive attitude toward conservation, and are wellinformed about the program are more likely to renew their contracts.

All of the significant determinants (at the 1\% level) in the re-enrollment model are also significant and have the same sign as in the participation model. Thus, reenrollment seems to respond to the same observed characteristics that affect the initial participation decision. In other words, the observed factors that attract landowners to participate in the program also tend to encourage participants to remain in the program at the end of the initial contract. This finding is important for policy and practice because it implies that interventions directed at increasing initial participation are also likely to increase re-enrollment. In our example, policy interventions that familiarize landowners with incentive programs, such as information outreach, 
promote re-enrollment as well as initial participation, most likely by reducing landowners' transaction costs.

The correlation between the re-enrollment and participation errors is positive and significant at the 5\% level, which indicates that those unobserved attributes that make landowners more likely to participate also cause them to be more likely to re-enroll. This suggests that unobserved characteristics, for example, landowners' inattention to incentives and their attitudes toward resource managers, have similar impacts on the initial participation and re-enrollment decisions.

More importantly, the statistically significant correlation between the two errors (i.e. unobservable random factors) indicates that the separate re-enrollment model would suffer from selection bias. Indeed, the magnitudes of the unconditional marginal effects from the separate re-enrollment model are smaller than those obtained using the joint model that controls for selection bias. The separate model underestimates the marginal effects by between $12 \%$ and $48 \%$. For example, the conditional marginal effect of Well-Informed indicates that well-informed participants are 16.5\% more likely to re-enroll, while the separate model estimate indicates a $12.6 \%$ higher re-enrollment probability. This underestimation suggests that the unobserved random noise in the self-selection of participants is correlated with landowner familiarity with incentive programs.

The extent to which the policy intervention that reduces landowners' transaction cost (e.g. information outreach) affects participation and re-enrollment could have significant effects on the performance of conservation incentive schemes. Our results provide the first empirical evidence that information outreach improves re-enrollment, even after controlling for the observed self-selection of participants who are more likely to acquire relevant information and remain in the program than a random landowner.

\section{References}

Ando, A. W., \& Chen, X. (2011). Optimal contract lengths for voluntary ecosystem service provision with varied dynamic benefit functions. Conservation letters, 4(3), 207-218. 
Barnes, J., Dayer, A., Sketch, M., Gramza, A., Nocera, T., Steinmetz, A., \& Sorice, M. (2019). Landowners and the Conservation Reserve Program: Understanding needs and motivations to cultivate participation, retention, and ongoing stewardship behavior. 105 pp. Available at http://hdl.handle.net/10919/88444

Beach, R. H., Pattanayak, S. K., Yang, J. C., Murray, B. C., \& Abt, R. C. (2005). Econometric studies of non-industrial private forest management: a review and synthesis. Forest Policy and Economics, 7(3), 261-281.

Bell, C. D., Roberts, R. K., English, B. C., \& Park, W. M. (1994). A logit analysis of participation in Tennessee's Forest Stewardship Program. Journal of Agricultural and Applied Economics, 26(2), 463-472.

Caldas, M. M., Bergtold, J. S., Peterson, J. M., \& Earnhart, D. H. (2016). Land-use choices: the case of conservation reserve program (CRP) re-enrollment in Kansas, USA. Journal of Land Use Science, 11(5), 579-594.

Chen, X., Lupi, F., He, G., Ouyang, Z., \& Liu, J. (2009). Factors affecting land reconversion plans following a payment for ecosystem service program. Biological Conservation, 142(8), 1740-1747.

Cooper, J. C., \& Osborn, C. T. (1998). The effect of rental rates on the extension of conservation reserve program contracts. American Journal of Agricultural Economics, 80(1), 184-194.

Dahl, G. B., Løken, K. V., \& Mogstad, M. (2014). Peer effects in program participation. American Economic Review, 104(7), 2049-74.

Dayer, A. A., Lutter, S. H., Sesser, K. A., Hickey, C. M., \& Gardali, T. (2018). Private landowner conservation behavior following participation in voluntary incentive programs: recommendations to facilitate behavioral persistence. Conservation Letters, 11(2), e12394.

Defrancesco, E., Gatto, P., \& Mozzato, D. (2018). To leave or not to leave? Understanding determinants of farmers' choices to remain in or abandon agrienvironmental schemes. Land use policy, 76, 460-470.

Duflo, E., \& Saez, E. (2003). The role of information and social interactions in retirement plan decisions: Evidence from a randomized experiment. The Quarterly journal of economics, 118(3), 815-842.

Engel, S., Pagiola, S., \& Wunder, S. (2008). Designing payments for environmental services in theory and practice: An overview of the issues. Ecological economics, 65(4), 663-674.

Fehr, E., \& Gächter, S. (2000). Fairness and retaliation: The economics of reciprocity. Journal of economic perspectives, 14(3), 159-181.

Forest Agency of Japan (2017). Annual Report on Forest and Forestry in Japan, fiscal year 2017. ZENRINKYOU.

Greene, W. H. (2003). Econometric analysis. Pearson Education India.

Hanley, N., Banerjee, S., Lennox, G. D., \& Armsworth, P. R. (2012). How should we incentivize private landowners to 'produce' more biodiversity?. Oxford Review of Economic Policy, 28(1), 93-113.

Heckman, J. J. (1979). Sample selection bias as a specification error. Econometrica: Journal of the econometric society, 153-161.

Hellerstein, D. M. (2017). The US Conservation Reserve Program: the evolution of an enrollment mechanism. Land Use Policy, 63, 601-610.

Kamal, S., Grodzińska-Jurczak, M., \& Brown, G. (2015). Conservation on private land: a review of global strategies with a proposed classification system. Journal of Environmental Planning and Management, 58(4), 576-597. 
Kilgore, M. A., Snyder, S. A., Schertz, J., \& Taff, S. J. (2008). What does it take to get family forest owners to enroll in a forest stewardship-type program?. Forest Policy and Economics, 10(7-8), 507-514.

Kuhfuss, L., Préget, R., Thoyer, S., Hanley, N., Le Coent, P., \& Désolé, M. (2016). Nudges, social norms, and permanence in agri-environmental schemes. Land Economics, 92(4), 641-655.

Langpap, C. (2004). Conservation incentives programs for endangered species: an analysis of landowner participation. Land Economics, 80(3), 375-388.

Langpap, C., \& Kim, T. (2010). Literature review: an economic analysis of incentives for carbon sequestration on nonindustrial private forests (NIPFs). Alig, RJ, tech. coord. Economic modeling of effects of climate change on the forest sector and mitigation options: a compendium of briefing papers. Gen. Tech. Rep. PNWGTR833. Portland, OR: US Department of Agriculture, Forest Service, Pacific Northwest Research Station, 109-142.

Lastra-Bravo, X. B., Hubbard, C., Garrod, G., \& Tolón-Becerra, A. (2015). What drives farmers' participation in EU agri-environmental schemes?: Results from a qualitative meta-analysis. Environmental Science \& Policy, 54, 1-9.

Lienhoop, N., \& Brouwer, R. (2015). Agri-environmental policy valuation: Farmers' contract design preferences for afforestation schemes. Land use policy, 42, 568577.

Lindhjem, H., \& Mitani, Y. (2012). Forest owners' willingness to accept compensation for voluntary conservation: A contingent valuation approach. Journal of Forest Economics, 18, 290-302.

Lutter, S. H., Dayer, A. A., \& Larkin, J. L. (2019). Young Forest Conservation Incentive Programs: Explaining Re-Enrollment and Post-program Persistence. Environmental management, 63(2), 270-281.

Ministry of Agriculture Forestry and Fisheries (2019). 2015 Census of Agriculture and Forestry. Retrieved from http://www.maff.go.jp/e/data/stat/

Mitani, Y., \& Lindhjem, H. (2015). Forest owners' participation in voluntary biodiversity conservation: what does it take to forgo forestry for eternity? Land Economics, 91(2), 235-251.

Mitani, Y., \& Lindhjem, H. (2021). Meta-analysis of landowner participation in voluntary incentive programs for provision of forest ecosystem services. Conservation Biology. https://doi.org/10.1111/cobi.13729

Rabotyagov, S. S., \& Lin, S. (2013). Small forest landowner preferences for working forest conservation contract attributes: A case of Washington State, USA. Journal of forest economics, 19(3), 307-330.

Reimer, A., Thompson, A., Prokopy, L. S., Arbuckle, J. G., Genskow, K., JacksonSmith, D., \& Nowak, P. (2014). People, place, behavior, and context: A research agenda for expanding our understanding of what motivates farmers' conservation behaviors. Journal of Soil and Water Conservation, 69(2), 57A-61A.

Riley, M. (2016). How does longer term participation in agri-environment schemes [re]shape farmers' environmental dispositions and identities? Land Use Policy, $52,62-75$.

Roberts, M. J., \& Lubowski, R. N. (2007). Enduring impacts of land retirement policies: evidence from the Conservation Reserve Program. Land Economics, 83(4), 516-538.

Shah, P., \& Ando, A. W. (2016). Permanent and temporary policy incentives for conservation under stochastic returns from competing land uses. American Journal of Agricultural Economics, 98(4), 1074-1094. 
Stubbs, M. (2014). Conservation Reserve Program (CRP): status and issues. Library of Congress, Congressional Research Service.

Van de Ven, W. P., \& Van Praag, B. M. (1981). The demand for deductibles in private health insurance: A probit model with sample selection. Journal of econometrics, 17(2), 229-252.

Wallander, S., Ferraro, P., \& Higgins, N. (2017). Addressing Participant Inattention in Federal Programs: A Field Experiment with The Conservation Reserve Program. American Journal of Agricultural Economics, 99(4), 914-931.

Wooldridge, J. M. (2010). Econometric analysis of cross section and panel data. MIT press.

Yeboah, F. K., Lupi, F., \& Kaplowitz, M. D. (2015). Agricultural landowners' willingness to participate in a filter strip program for watershed protection. Land use policy, 49, 75-85. 


\section{Appendix I National-Level Incentive Programs in Japan}

A variety of incentive-based policies are currently operational in Japan. There are two national-level forest incentive schemes: a conservation-based policy (the Protection Forests Scheme) and a management-based policy (the Forest Management Plan). The Protection Forests Scheme is designed to protect the forest functions that serve and benefit the public. Landowners with eligible forestland, which are designated by the government or province as such, enter into voluntary agreements with the government in which the level of timber harvest and land conversion on their land is restricted. They can instead capture a tax benefit. The Forest Management Plan seeks to encourage forestland owners to implement joint forest management. Effective joint management of a sufficient amount of forestland can enhance forest ecosystem services. The government incentivizes forest owners to develop joint management plans for sustainable forest management and conservation by offering subsidies and tax exemption. The KJM program is the second regional program designed under this national Forest Management Plan subsidy scheme.

\section{Appendix II Survey Excerpt}

[Participation]

2.4. Do you participate in the KJM program?

Yes

No

[Re-enrollment]

2.7. (For participants only) The contract length of the KJM program is set at 5 years. Assume that your contract is approaching expiration. Will you renew your contract when it expires?

Yes, I will renew my contract.

No, I will not renew my contract and manage my forest on my own.

No, I will not renew my contract and ask someone else to manage my forest.

No, I will neither renew my contract nor manage my forest.

\section{Appendix III Derivation of Equation (4)}

The joint normal distribution of $u_{i}$ and $v_{i}$ with mean $\mathbf{0}$ and covariance matrix $\boldsymbol{\Sigma}$ is given by: 


$$
f\left(u_{i}, v_{i}\right)=\frac{\exp \left(-\frac{1}{2}\left(\begin{array}{ll}
u_{i} & v_{i}
\end{array}\right) \Sigma^{-1}\left(\begin{array}{ll}
u_{i} & v_{i}
\end{array}\right)^{\prime}\right)}{\sqrt{(2 \pi)^{2}|\Sigma|}} .
$$

When each variable has unit variance and covariance $\rho$, the joint distribution can be rewritten as:

$$
\begin{aligned}
f\left(u_{i}, v_{i}\right) & =\frac{1}{\sqrt{(2 \pi)^{2}\left(1-\rho^{2}\right)}} \exp \left(-\frac{1}{2} \cdot \frac{u_{i}^{2}-2 \rho u_{i} v_{i}+v_{i}^{2}}{1-\rho^{2}}\right) \\
& =\frac{1}{\sqrt{(2 \pi)^{2}\left(1-\rho^{2}\right)}} \exp \left(-\frac{1}{2} \cdot \frac{\left(u_{i}-\rho v_{i}\right)^{2}+v_{i}^{2}\left(1-\rho^{2}\right)}{1-\rho^{2}}\right) \\
& =\frac{1}{\sqrt{2 \pi}} \exp \left(-\frac{v_{i}^{2}}{2}\right) \times \frac{1}{\sqrt{2 \pi\left(1-\rho^{2}\right)}} \exp \left(-\frac{1}{2} \cdot \frac{\left(u_{i}-\rho v_{i}\right)^{2}}{1-\rho^{2}}\right)
\end{aligned}
$$

Hence, the re-enrollment probability conditional on $\mathbf{x}_{i}$ and $v_{i}$ is:

$$
\begin{aligned}
\operatorname{Pr}\left(y_{i}=1 \mid \mathbf{x}_{i}, v_{i}\right) & =\int_{-\mathbf{x}_{i} \boldsymbol{\beta}}^{\infty} \phi\left(u \mid v_{i}\right) d u \quad \text { (independence) } \\
& =\int_{-\mathbf{x}_{i} \boldsymbol{\beta}}^{\infty} \frac{f\left(u, v_{i}\right)}{\phi\left(v_{i}\right)} d u \\
& =\int_{-\mathbf{x}_{i} \boldsymbol{\beta}}^{\infty} \frac{1}{\sqrt{2 \pi\left(1-\rho^{2}\right)}} \exp \left(-\frac{1}{2} \cdot \frac{\left(u-\rho v_{i}\right)^{2}}{1-\rho^{2}}\right) d u \\
& =\boldsymbol{\Phi}\left[\frac{\mathbf{x}_{i} \boldsymbol{\beta}+\rho v_{i}}{\sqrt{1-\rho^{2}}}\right] .
\end{aligned}
$$

Conditioning on participation is equivalent to conditioning on $v_{i} \geq-\mathbf{z}_{i} \boldsymbol{\delta}$. Therefore, the re-enrollment probability conditional on $\mathbf{x}_{i}$ and participation is:

$$
\begin{aligned}
\operatorname{Pr}\left(y_{i}=1 \mid \mathbf{x}_{i}, v_{i}\right. & =\mathrm{E}\left[\operatorname{Pr}\left(y_{i}=1 \mid \mathbf{x}_{i}, v_{i}\right) \mid \mathbf{x}_{i}, v_{i} \geq-\mathbf{z}_{i} \boldsymbol{\delta}\right] \\
\left.\geq-\mathbf{z}_{i} \boldsymbol{\delta}\right) & =\mathrm{E}\left[\boldsymbol{\Phi}\left[\frac{\mathbf{x}_{i} \boldsymbol{\beta}+\rho v_{i}}{\sqrt{1-\rho^{2}}}\right] \mid \mathbf{x}_{i}, v_{i} \geq-\mathbf{z}_{i} \boldsymbol{\delta}\right] \\
& =\frac{1}{\boldsymbol{\Phi}\left(\mathbf{z}_{i} \boldsymbol{\delta}\right)} \int_{-\mathbf{z}_{i} \boldsymbol{\delta}}^{\infty} \boldsymbol{\Phi}\left[\frac{\mathbf{x}_{i} \boldsymbol{\beta}+\rho s}{\sqrt{1-\rho^{2}}}\right] \phi(s) d s .
\end{aligned}
$$

The last equation uses a basic fact regarding truncated normal distribution.

\section{Appendix IV Sensitivity Analysis}




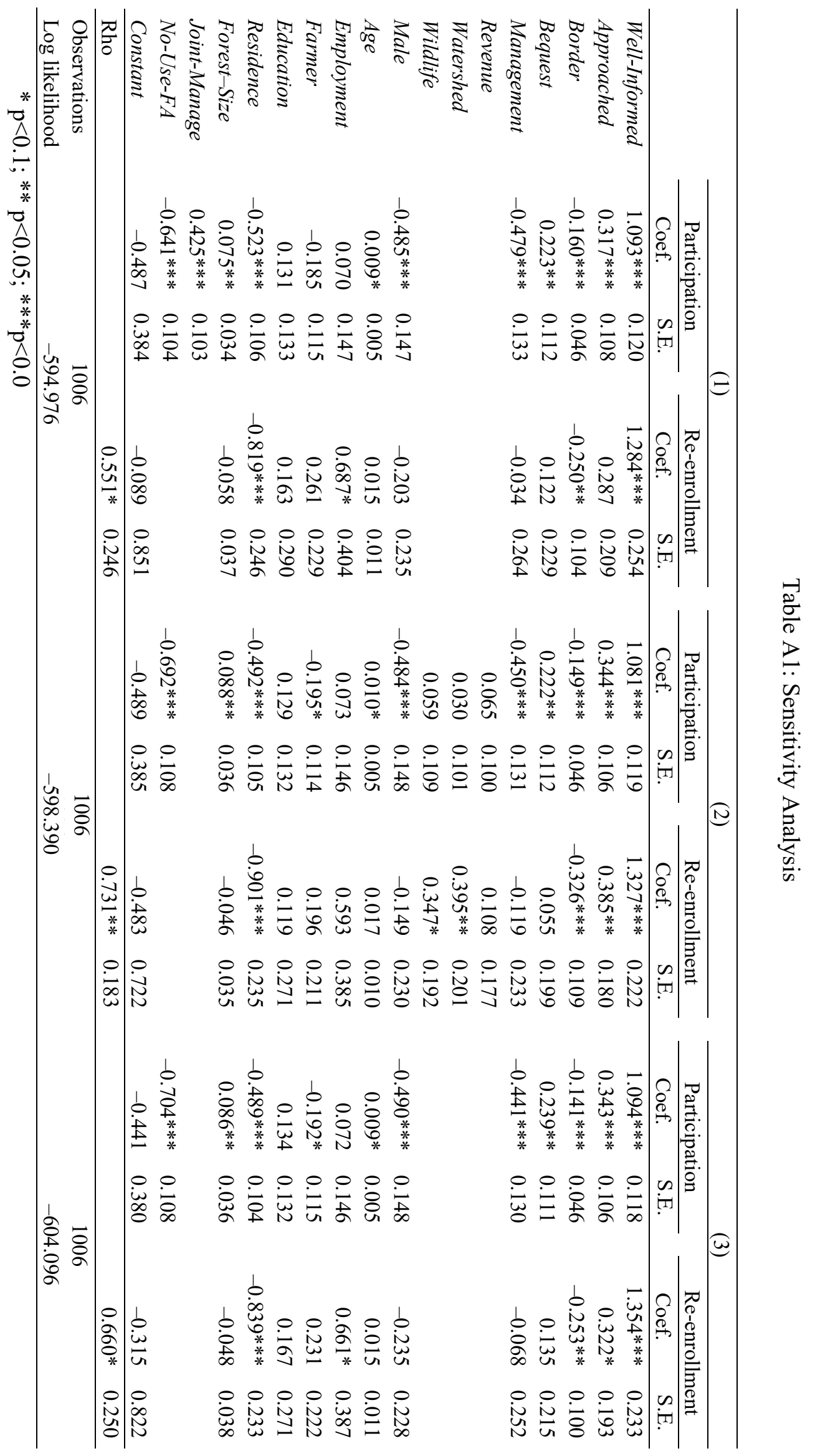

